\title{
HeLa 细胞的核仁骨架
}

\section{焦仁杰 陈建明 朱小健 宋为群 翟中和}

(北京大学生物学系, 北京 100871)

\section{关键词 HeLa 细胞、核仁骨架、重组装、选择性抽提}

核仁是 rRNA 前体合成及核糖体装配的场所. 核仁内部结构是由许多拷贝的 rDNA, rRNA 及若干种蛋白质所组成. rRNA 前体的加工过程也在核仁内部进行并且与一些非核糖 体蛋白有关. 80 年代中期, 科学家们根据一些实验推测核仁中除了存在大量 rRNA 转录前体 及前核糖体颗粒外, 还存在一个由蛋白质组成的支架结构, 它在决定 rRNA 基因的空间分布 及转运中可能起作用, 这种结构就称为核仁骨架 (nucleolar skeleton) 或核仁基质 (nucleolar matrix $)^{[1-3]}$. 然而, 至今关于核仁骨架的形态结构, 组成成分以及它的功能都是不清楚的. 我们 用体外培养的 HeLa 细胞经选择性抽提, 特别是经由低盐到高盐的梯度抽提后, 结合 DGD 包 埋去包埋剂超薄切片技术, 首先在电镜下清晰地显示了核仁骨架的结构; 然后又使核仁骨架 蛋白组分在体外进行重组装, 并且发现能够进行重新组装的蛋白组分主要是 68,36 与 $16 \mathrm{kD}$ 蛋白.

\section{1 材 料 和 方 法}

\section{1 细胞及其培养}

$\mathrm{HeLa}$ 传代细胞以含有 $0.003 \%$ 谷氨酰胺和 $10 \%$ 小牛血清 E-MEM 培养基在体外进行单 层静置培养. 取长成良好单层的细胞进行下述实验.

\section{2 细胞的选择性抽提}

参照焦仁杰等的方法 ${ }^{[4]}$. 本实验在抽提过程中采用由低盐到高盐梯度抽提的方法, 即在 0.25 $\mathrm{mol} / \mathrm{L}\left(\mathrm{NH}_{4}\right)_{2} \mathrm{SO}_{4}$ 作用 $5 \mathrm{~min}$ 后, 继续用 $2 \mathrm{~mol} / \mathrm{L} \mathrm{NaCl}$ 抽提 $10 \mathrm{~min}$, 以显示核仁骨架的内部结构.

\subsection{DGD 包埋样品的制备}

参照翟中和等的方法 ${ }^{[?]}$.

\section{$1.4 \mathrm{HeLa}$ 细胞核仁的分离及核仁骨架的制备}

长成良好单层的 HeLa 细胞用 PBS (pH6.8) 洗涤两次后收集, 离心, 沉淀后用含有 $10 \mathrm{mmol} / \mathrm{L}$ Tris- $\mathrm{HCl}, \mathrm{pH} 7.4,12 \mathrm{mmol} / \mathrm{L} \mathrm{MgCl}_{2}$ 的 $0.88 \mathrm{~mol} / \mathrm{L}$ 蔗糖溶液悬浮, 采用超声波的方法破碎细胞, 输出控制 40-50\%, 破碎 $30 \mathrm{~s}$, 间隙 $10 \mathrm{~s}$, 光镜检查直至细胞核破碎, 核仁游离出来为止. $10000 \times \mathrm{g}$ 离心 $10 \mathrm{~min}$ 便可得到粗提的核仁, 光镜检查核仁的纯度可达到 $90 \%$ 以上. 以上操作均在低温 下进行, 并在缓冲液中加人适量的蛋白酶抑制剂.

核仁组分首先用 $100-200 \mu \mathrm{g} / \mathrm{ml}$ 的 DNaseI 消化 $30 \mathrm{~min}$ 除去核仁内染色质 (rDNA) 结 构, 继而用 $0.25 \mathrm{~mol} / \mathrm{L}\left(\mathrm{NH}_{4}\right)_{2} \mathrm{SO}_{4}$ 和 $2 \mathrm{~mol} / \mathrm{L} \mathrm{NaCl}$ 相继抽提去除多数核仁骨架结合蛋白, 
$10000 \times \mathrm{g}$ 离心 $10 \mathrm{~min}$, 沉淀即是所制备的核仁骨架样品.

\section{5 核仁骨架的重组装}

上述所得到的样品用 $9 \mathrm{~mol} / \mathrm{L}$ 尿素 (含 $10 \mathrm{mmol} / \mathrm{L} \beta$-颈基乙醇, $\mathrm{pH} 7.6$ ) 于 $37^{\circ} \mathrm{C}$ 溶解 $2 \mathrm{~h}$, $100000 \times \mathrm{g}$ 离心 $2 \mathrm{~h}$, 以除去不溶杂质. 上清液装人透析袋透析, 第一次透析液含 $10 \mathrm{mmol} / \mathrm{L}$ Tris- $\mathrm{HCl}(\mathrm{pH} 7.6), 10 \mathrm{mmol} / \mathrm{L} \quad \beta$ - 琉基乙醇, 第二次透析液含 $50 \mathrm{mmol} / \mathrm{L}$ Tris- $\mathrm{HCl}$ (pH7.5), $10 \mathrm{mmol} / \mathrm{L} \beta$ - 巯基乙醇, $5 \mathrm{mmol} / \mathrm{L}$ EDTA. 每次透析 $6 \mathrm{~h}$ 以上,并在低温下进行.

将透析后的样品滴到覆有 Formvar 膜的铜网上, 吸附一段时间后用磷铇酸进行负染色, 透射电镜观察.

\section{6 重组装核仁骨架蛋白成分分析}

上述透析后的样品用常规 SDS 聚丙烯酰胺凝胶电泳分析. 浓缩胶浓度为 $4 \%$, 分离胶浓 度为 $8.5 \%$. 考马斯亮蓝染色.

\section{2 结 果 与 讨 论}

\section{1 核仁骨架的形态结构}
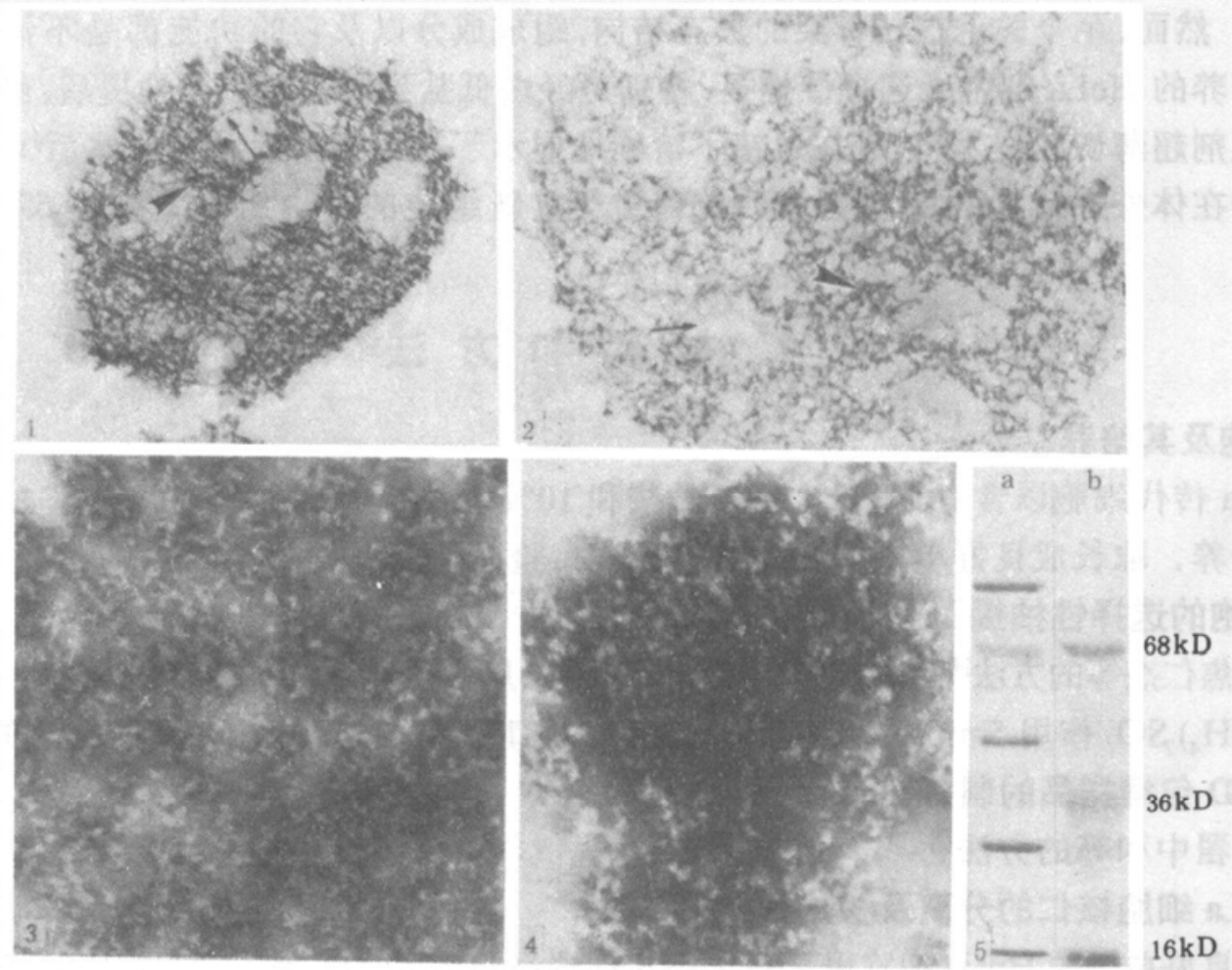

图 1-5

1. HeLa 细胞经 TritonX-100 等选择性抽提后,其核仁内部显示出一个网络结构,而对应于原来核仁的纤维中心 区呈“空洞”结构. 箭号 $(\rightarrow)$ 所示为纤维样结构, 箭头 $(\rightarrow)$ 所示为颗粒样结构. $\times 24800$;

2. 样品及制备方法同图 1, 可以明显区别组成 HeLa 细胞核仁骨架的两种形态结构: 纤维样结构与颗粒样结构, 箭号 $(\rightarrow)$ 所示为纤维样结构, 箭头 $(\rightarrow)$ 所示为颗粒样结构. $\times 26400$;

3. 核仁骨架成分经尿素溶解后在体外能组装成核仁骨架的两种基本结构. $\times 36000$;

4. 体外组装的核仁骨架基本结构可以通过某种蛋白的组织聚集形成类似的核仁骨架． $\times 36000$;

5. 能组装成核仁骨架的蛋白成分的 SDS-PAGE 分析结果 a. 标准蛋白, 自上至下分子量分别为 $94,67,43,30$ $17.5 \mathrm{kD}$ b. 核仁骨架蛋白成分, 主要包括 68,36 和 $16 \mathrm{kD}$ 蛋白 
体外培养的 HeLa 细胞经去垢剂、DNA 酶并结合由低盐到高盐的顺序抽提后, 在其核仁内 部显示出一个致密的网络即核仁骨架结构 (图 1,2). 在电镜下, HeLa 细胞的核仁骨架主要有 两种形态特征: 纤维样结构与颗粒样结构. 纤维构成了核仁骨架网络的主体, 其上附着许多棵粒 状物质, 它们具有共同的抗高盐抽提特性. 通过大量电镜观察可以发现, 对应于核仁的纤维中 心区域的核仁骨架中常出现 “空洞” 结构 (图 1), 说明核仁骨架可能主要在核仁的颗粒区存在, 并 发挥作用. 然而, 在某些 “空洞” 处也会看到有纤维相连 (图 2). Franke 等人 1981 年就首先报 道了爪蟾卵母细胞中经 $2 \mathrm{~mol} / \mathrm{L} \mathrm{NaCl}$ 抽提后存留的核仁残余, 其内部结构难于区分; Olson 等 人也于 1983 年和 1986 年分别报道了核仁基质的主要成分. 确切地说, 这些年对核仁骨架研 究还处于初始阶段, 我们认为其中的主要原因是分别用高盐或低盐抽提都很难保持核仁骨架 的精细结构, 因为高盐处理易使 RNP 颗粒快速凝聚, 这样阻碍了核仁骨架的进一步显示. 本 文采用低盐结合高盐顺序抽提的方法, 结合 DGD 包埋去包埋剂超薄切片技术, 首先在电镜下 清晰地显示了 $\mathrm{HeLa}$ 细胞核仁骨架的精细结构. 我们至今还未见到这方面的文献报道, 更没 有见到象我们现在显示出如此清晰的核仁骨架网络.

\section{2 核仁骨架的体外组装与成分分析}

用差速离心的方法分离核仁组分, 经选择性的抽提后存留下的核仁骨架成分主要是水不溶 性的蛋白质成分. 将这样的样品溶于尿素, 再经过透析去除尿素和盐后发现核仁骨架成分在 体外能组装成类似的骨架结构 (图 3,4), 同样可以看到纤维样结构与颗粒样结构. 更令人感兴趣 的是这种体外组装的核仁骨架结构还能聚集形成类似核仁的结构 (图 4), 我们推测可能某种核 仁骨架成分在此起了核仁形成的组织者的作用. 应用 SDS-PAGE 对透析后的样品进行分 析, 发现能体外组装成核仁骨架的蛋白质组分主要包括 $68,44,36,16$ 及 $43-55 \mathrm{kD}$ 之间 的蛋白成分, 其中 68 和 $36 \mathrm{kD}$ 蛋白含量较大 (图 5). 关于核仁骨架蛋白的性质及其与 rDNA 的关系是我们要进一步解决的课题.

\section{参考文献}

[1] Franke, W. W. et al., J. Cell Biol., 1981, 90:289-299.

[2] Olson, M. O. J. et al., Biochemistry, 1986, 25:5745-5751.

[3] Elizabeth, C. et al., Eur. J. Cell Bioi., 1989, 50:353-359.

[4] Jiao, R., Zhai, Z., Proc. 5APEM, 1992, (2):414-415.

[ 5] 䍜中和等, 中国科学, B 辑, 1987, (12): 1076-1084. 